\title{
Sex and Personality Differences in Job Value Preferences
}

\author{
Adrian Furnham ${ }^{1,2}$, Geoff Trickey ${ }^{3}$, Gillian Hyde ${ }^{3}$ \\ ${ }^{1}$ Research Department of Clinical, Educational and Health Psychology, University College London, London, UK \\ ${ }^{2}$ Norwegian Business School (BI), Nydalveien, Olso, Norway \\ ${ }^{3} \mathrm{PCL}$, Tunbridge Wells, UK \\ Email: a.furnham@ucl.ac.uk
}

Received 29 March 2016; accepted 10 May 2016; published 13 May 2016

Copyright (C) 2016 by authors and Scientific Research Publishing Inc.

This work is licensed under the Creative Commons Attribution International License (CC BY).

http://creativecommons.org/licenses/by/4.0/

(c) (i) Open Access

\begin{abstract}
One thousand four hundred and fifty-eight business executives completed the two Hogan assessment measures: the Motives, Values and Preferences Inventory (MVPI) (an inventory of ten core occupational values), and the Hogan Personality Inventory (HPI) (a measure of seven super-factor traits). There were seven sex differences on the values which factored into three interpretable factors labelled Science, Excitement and Virtue. Regression with the factor scores as the criterion variables and demography and the seven HPI scales as predictor variables showed a quarter to a half of the variance could be explained. The second factor Excitement was most clearly related to HPI scores. Implications for selection are considered.
\end{abstract}

\section{Keywords}

Traits, Values, Motives, Gender

\section{Introduction}

There are many taxonomies of values and value systems in the area of personality and vocational psychology (Holland, 1985). Most value instruments are used to help make decisions on vocational choice and change. Inevitably there have been various attempts to examine the relationship between personality measures and values mainly using the Holland measure (Costa, McCrae, \& Holland, 1984; De Fruyt \& Mervielde, 1997; Furnham, 1994; Goh \& Leong, 1993; Schinka, Dye, \& Curtiss, 1997; Tokar \& Swanson, 1995).

This study will use the R. Hogan and J. Hogan (1997) Motives, Values, Preferences Inventory (MVPI) which is a modern, psychometrically valid measure with impressive adult norms. It measures 10 values set out in Table 1. It is based on Holland's work and ideas (Hogan \& Blake, 1999), which will be described in due course. 
These values were arrived at by a content analysis of the literature including the taxonomies of five authors working in the area (Hogan, R. \& Hogan, J., 1997: p. 11). A principal component analysis yielded four factors relating to Holland's enterprising, social, conventional and investigative types.

Concurrent validity with various other measures are reported in the manual. Correlations with the MBTI (Myers, Mc Caulley, \& Most, 1985) showed the Affiliation scale a good marker (i.e., consistent high correlate) for Extraversion-Introversion (EI), Aesthetics and Security for Sensing-Intuition (SN); Altruism for ThinkingFeeling (TF) and Security and Tradition for Judging-Perceiving (JP). They also reported correlations with the seven factor Hogan Personality Inventory (Hogan, R. \& Hogan, J., 1995). Many correlations were significant ( $N$ $=2692$ ), but nine were $r>0.30$. They showed Adjustment (Neuroticism) negatively related to Hedonism; Ambition positively correlated with Affiliation; Sociability with both Affiliation and Recognition; Likeability (Agreeableness) with Affiliation; Prudence positively with Security and Tradition but negatively with Hedonism; Intellect (Openness) with Aesthetic and School Success with no values $(r>0.20)$. Similarly, correlations with the Hogan Developmental Survey (Hogan, R. \& Hogan, J., 1997), showed thirteen of the correlations (110 in all) were $r>0.40(N=145)$. Considered as markers of the disordered the following were found: Affiliation (negative) for Reserved, Excitable and Cautious; Recognition for Imaginative; Affiliation, Power and Recognition for Colourful; Commercial, Power and Recognition for Bold; Security for Diligent and Power and Recognition for Mischievous.

More recently, Furnham, Hyde and Trickey (2013) in a study of over 2000 British adults, found the MVPI factored into three interpretable factors. Further, they found that three dark-side factors (Moving Against, Moving Away From and Moving Toward others) accounted for around a third of the variance in preferences for the value factors.

This study attempts to replicate and extend the above study using "bright-” rather than "dark-" side variables. The aim is to explore the relationship between the Hogan Personality Inventory, Super-Seven, personality traits and values in the workplace.

\section{Method}

\subsection{Participants}

There were 1458 participants of which 809 were male. Their ages ranged from 21 to 63 years with a mean of 36.14 years, $S D=12.90$ ). Nearly all were native white Britons. They were all at a managerial level in a large, mostly multi-national organisation. All participants took part in an assessment centre sponsored by their organiation and designed and led by the second and third author.

\subsection{Measures}

Values. The Motives, Values, Preferences Inventory (MVPI, Hogan, R. \& Hogan, J., 1999) measures 10 Motives/Preferences. Each scale is composed of five themes: 1) Lifestyles, which concern the manner in which a person would like to live; 2) Beliefs, which involve 'shoulds', ideals and ultimate life goals; 3) Occupational Preferences, which include the work an individual would like to do, what constitutes a good job, and preferred work materials; 4) Aversions, which reflect attitudes and behaviours that are either disliked or distressing; and 5) preferred Associates, which include the kind of persons desired as co-workers and friends. MVPI scores are quite stable over time, with test-retest reliabilities ranging between 0.64 and $0.88(M=0.79)$. More than 100 validation studies have been conducted on the MVPI with results indicating that the inventory is effective in predicting job performance and outcome variables such as turnover.

Personality. Hogan Personality Inventory (Hogan, R. \& Hogan, J., 1997) is a measure of normal personality functioning closely aligned to the Big Five. It measures seven dimensions of personality: Adjustment, Ambition, Sociability, Interpersonal Sensitivity, Prudence, Inquisitive and Learning Approach. The manual provides evidence of the tests reliability and validity and many papers have been published that used it (Hogan, Barrett, \& Hogan, 2007; Sheppard, Han, Colarelli, Dai, \& King, 2006; Stevens, Guthrie, Ash, \& Coate, 2002).

\subsection{Procedure}

Participants were tested in an assessment centre and given feedback on their performance. Nearly all were native English speakers or else completely competent and confident in the language. They came from a wide range of 
organisations in the private and public sector. Participants agreed to take part and were given detailed personal feedback on the questionnaire. The anonymised data was analysed by the first author.

\section{Results}

\section{Statistical Analysis}

Three analyses were completed: First an analysis of variance to explore sex differences in values; second a factor analysis of the 10 item value scale and third, a step-wise multiple regression with the value factor scores as the dependent variable and the demographic factors and the personality traits as the predictor varaiables.

\subsection{Sex Differences}

Table 1 shows the mean scores, the sex difference analyses and the factor analytic results.

The results indicated that the three values most highly endorsed were Affiliation, Altruism and Power, while

Table 1. Sex differences and factor analytic scores.

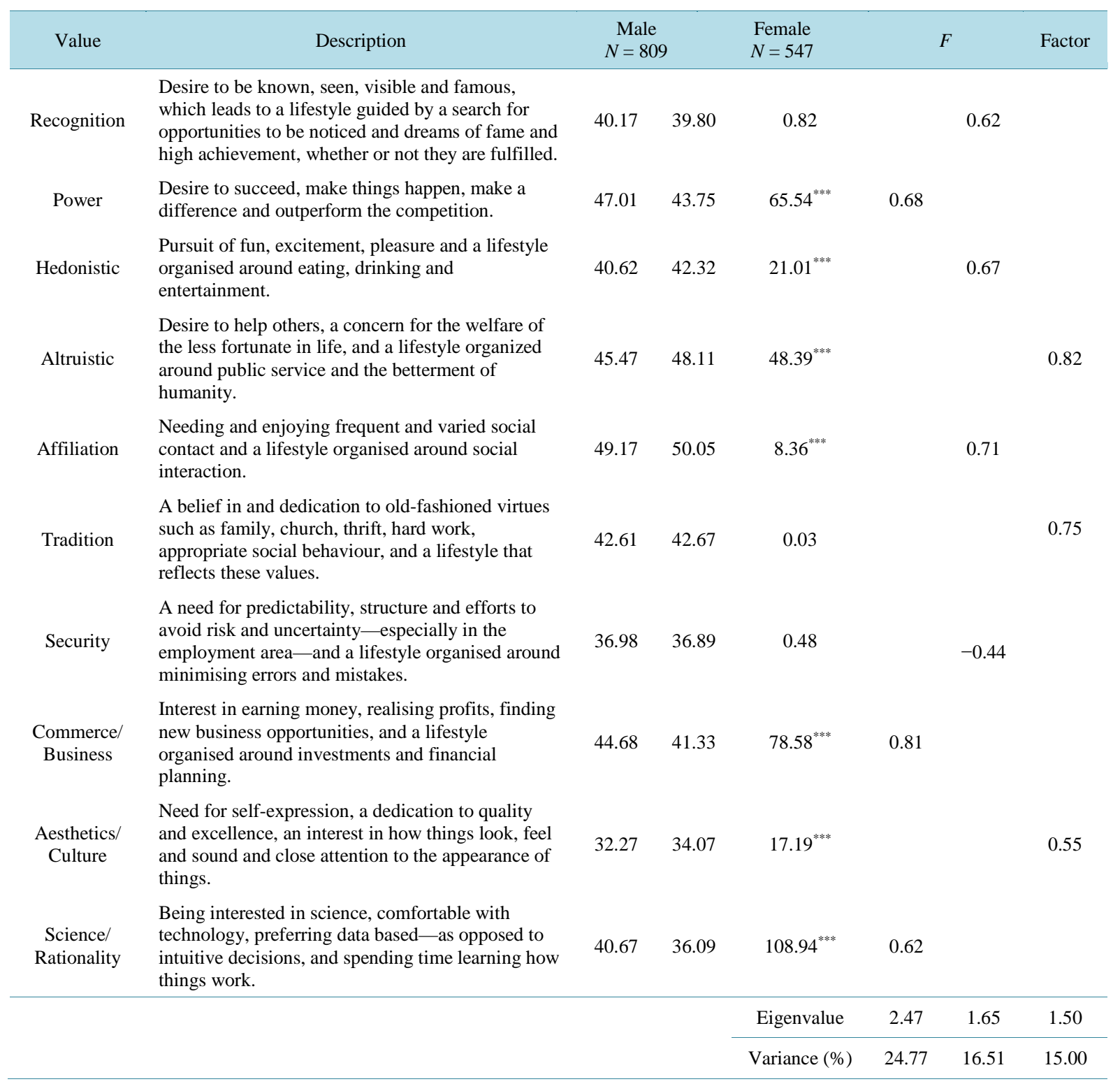

Note. ${ }^{*} p<0.01$ 
those with lowest endorsement were Aesthetics (Security and Hedonism). There were significant sex differences on seven, indicating males had higher scores on Power, Commerce and Science but lower scores on Hedonism, Altruism, Affiliation and Aesthetics. The exploratory VARIMAX rotated factor analysis yielded three clear factors labelled Business/Science, Excitement and Virtue/Culture. The correlations between factor scores and the demographic variables showed few significant findings. Younger people tended to endorse the second factor (Excitement) more than older people. $(r=-0.12, p<0.01)$ Males endorsed the first factor (Business/Science) more than females $(r=0.28, p<0.001)$ who endorsed the second (Excitement) and third (Virtue/Culture) factor more $(r=0.08, p<0.01 ; r=0.18, p<0.001)$.

\subsection{Personality and Values}

Table 2 shows the results from the regressional results. First, the three value factors scores were regressed onto age, gender and social desirability, followed by the seven traits. For the first factor, Business/Science, the demographic factors accounted for $12 \%$ of the variance. Younger males with higher social desirability scores favoured Business/Science. Adding the seven personality traits double the variance explained: less adjusted and less interpersonally sensitive but more ambitious, prudent, and inquisitive were interested in this value. The second analysis showed that where sex, age and social desirability accounted for very little of the variance, five of the seven personality factors were closely related to Excitement: those high on Sociability, Interpersonal Sensitivity and Ambition, but low on Prudence and Inquisitiveness where interested in Excitement. The third factor showed older males, low on Adjustment and Ambition, but high on Interpersonal Sensitivity, Prudence, Inquisitiveness, and Learning Approach valued virtuous/cultural occupations with males favouring over females. Four of the dark side factors were strong predictors of this value showing that sceptical, reserved, bold and diligent people favoured this value. In all a third of the variance could be explained.

The second regression showed that whilst age, sex and social desirability could account for only $2 \%$ of the variance, an additional $45 \%$ was accounted for by various dark side factors of which the following were most important: those low on Reserved and Diligent, but high on Mischievious, Colourful, Bold and Excitable favoured this value. The final regression accounted for least of the variance. It showed older females and those low on excitable, sceptical, reserved and mischievous but high on cautious and imagative favoured this value.

\section{Discussion}

One way of attempting to understand a person's motivation is to understand the things they value. This study looked at bright-side personality correlates of work values. The ten item values questionnaire factored into three

Table 2. The results of the regression with the three factor scores as criterion variables and demographic and personality scores as the predictor variables.

\begin{tabular}{|c|c|c|c|c|c|c|}
\hline & \multicolumn{2}{|c|}{ Factor 1} & \multicolumn{2}{|c|}{ Factor 2} & \multicolumn{2}{|c|}{ Factor 3} \\
\hline & Beta & $t$ & Beta & $t$ & Beta & $t$ \\
\hline Age & -0.05 & $2.20^{* * *}$ & -0.06 & $3.22^{* * *}$ & 0.09 & $3.91^{* * *}$ \\
\hline Gender & -0.20 & $7.87^{* * *}$ & 0.11 & $5.09^{* * *}$ & 0.14 & $5.57^{* * *}$ \\
\hline Social desirability & 0.10 & $4.31^{*}$ & 0.05 & $2.38^{*}$ & 0.06 & $2.38^{* * *}$ \\
\hline Adjustment & -0.25 & $8.25^{* * *}$ & -0.05 & 1.84 & -0.17 & $5.28^{* * *}$ \\
\hline Ambition & 0.22 & $7.71^{* * *}$ & 0.07 & $3.03^{* * *}$ & -0.11 & $3.74^{* * *}$ \\
\hline Sociability & -0.04 & 1.50 & 0.54 & $22.61^{* * *}$ & -0.04 & 1.52 \\
\hline Interpersonal sensitivity & -0.21 & $7.35^{* * *}$ & 0.14 & $6.14^{* * *}$ & 0.29 & $10.42^{* * *}$ \\
\hline Prudence & 0.25 & $9.49^{* * *}$ & -0.24 & $10.53^{* * *}$ & 0.14 & $4.92^{* * *}$ \\
\hline Inquisitiveness & 0.25 & $9.62^{* * *}$ & -0.09 & $4.10^{* * *}$ & 0.28 & $10.49^{* * *}$ \\
\hline Learning Approach & 0.06 & $2.60^{* *}$ & -0.02 & 0.72 & 0.11 & $4.51^{* * *}$ \\
\hline Model 1 & \multicolumn{2}{|c|}{$F=68.84^{* * *}$} & \multicolumn{2}{|c|}{$F=10.60^{* * *}$} & \multicolumn{2}{|c|}{$F=22.61^{* * *}$} \\
\hline Adj $\mathrm{R}^{2}$ & \multicolumn{2}{|c|}{0.12} & \multicolumn{2}{|c|}{0.02} & \multicolumn{2}{|c|}{0.04} \\
\hline Model 2 & \multicolumn{2}{|c|}{$F=53.21^{* * *}$} & \multicolumn{2}{|c|}{$F=131.98^{* * *}$} & \multicolumn{2}{|c|}{$F=43.24^{* * *}$} \\
\hline Adj $R^{2}$ & \multicolumn{2}{|c|}{0.26} & \multicolumn{2}{|c|}{0.47} & \multicolumn{2}{|c|}{0.22} \\
\hline
\end{tabular}

Note. ${ }^{*} p<0.05, \stackrel{* *}{p}<0.01, \stackrel{* * *}{p}<<0.001$ 
interpretable factors. There have been numerous attempts to provide a simple clear structure to work values like the $2 \times 2$ ideas vs. data, things vs. people dimensions. This study showed first a data-rational, success-oriented, business factor. The best bright side factors were Prudence and Inquisitiveness and Ambition but also low Interpersonal Sensitivity and Adjustment. The literature on trait correlates of business success suggest high Consciousness (Prudence), high Openness (Inquisitiveness and Learning Approach), low Agreeableness (Interpersonal Sensitivity) but low Neuroticism (high Adjustment) (Furnham, 2008; Hogan 2006). The only surprising result in this study was those low on Adjustment expressing an interest in that value as data have shown that high Adjustment is associated with success in business and science. However low Adjustment can be associated with success on various jobs: all that edgy, driven, anxious motivation propels them to keep doing better, which could also be associated with scientific endeavour. Equally being too high on Adjustment can lead to complacency and insensitivity to the plight of others.

The second value factor was clearly more about people organisations that involved fame and fun. It was not therefore surprising that the three bright-side factors associated with this factor were high Sociability (Extraversion), Interpersonal Sensitivity (Agreeableness) and low Prudence (Conscientiousness). It was associated with modest Ambition but low Inquisitiveness.

The third value factor reflected occupations that were more traditionally around public service, respectability but also high standards. It was labelled virtue. The two bright-side factors most clearly related to this factor were Interpersonal Sensitivity and Inquisitiveness. Results also showed those who expressed an interest in this virtue tended to be high on Prudence and low on Ambition which may be expected of public service or charity employees.

This study provides concurrent validity for the MVPI. These work values are clearly and logically related not only to sex and age but also bright side personality. It should be recalled that these questionnaires were completed by working adults who had chosen their occupation rather than those actively searching for career advice. To this extent it may be anticipated that they were clear about their work values and had, for the most part, found jobs that fitted these values. The results showed a logical and interpretable pattern of relationships with each of the bright and dark side factors related specifically to the three factors.

One limitation of the study lay in the fact that the measures were based on self-report. Clearly, to reduce inflated correlations due to method invariance it would have been desirable to have other methods such as observer reports to validate the MVPI.

\section{References}

Costa, P., McCrae, R., \& Holland, J. (1984). Personality and Vocational Interests in an Adults Sample. Journal of Applied Psychology, 69, 390-400. http://dx.doi.org/10.1037/0021-9010.69.3.390

De Fruyt, F., \& Mervielde, I. (1997). The Five-Factor Model of Personality and Holland's RIASEC Interest Types. Personality and Individual Differences, 23, 87-103. http://dx.doi.org/10.1016/S0191-8869(97)00004-4

Furnham, A. (1994). Personality at Work: The Role of Individual Differences in the Workplace. Brighton: Psychology Press.

Furnham, A. (2008) Personality and Intelligence at Work. London: Routledge. http://dx.doi.org/10.4324/9780203938911

Furnham. A., Hyde, G., \& Trickey, G. (2013). The Dark Side of Career Preferences: Dark Side Traits, Motives and Values. Journal of Applied Social Psychology, 44, 106-114.

Goh, D., \& Leong, F. (1993). The Relationship between Holland's Theory of Vocational Interest and Eysenck’s Model of Personality. Personality and Individual Differences, 15, 555-562. http://dx.doi.org/10.1016/0191-8869(93)90339-5

Hogan, J., Barrett, P., \& Hogan, R. (2007) Personality Measurement, Faking, and Employment Status. Journal of Applied Psychology, 92, 1270-1285. http://dx.doi.org/10.1037/0021-9010.92.5.1270

Hogan, R. (2006). Personality and the Fate of Organisations. New York: Lawrence Erlbaum.

Hogan, R., \& Blake, R. (1999). John Holland's Vocational Typology and Personality Theory. Journal of Vocational Psychology, 55, 41-56. http://dx.doi.org/10.1006/jvbe.1999.1696

Hogan, R., \& Hogan, J. (1995). Hogan Personality Inventory Manual. Tulsa, OK: Hogan Assessment Systems.

Hogan, R., \& Hogan, J. (1997). Hogan Development Survey Manual. Tulsa, OK: Hogan Assessment Centres.

Hogan, R., \& Hogan, J. (1999). Motives, Values, Preferences Inventory Manual. Tulsa, OK: Hogan Assessment Centre.

Holland, J. (1985). Making Vocational Choices: A Theory of Vocational Personalities and Work Environments. Englewood Cliffs, NJ: Prentice Hall. 
Myers, I. B., McCaulley, M. H., \& Most, R. (1985). Manual, a Guide to the Development and Use of the Myers-Briggs type Indicator. New York: Consulting Psychologists Press.

Schinka, J., Dye, D., \& Curitss, G. (1997). Correspondence between Five-Factor and RIASEC Models of Personality. Journal of Personality Assessment, 68, 355-368. http://dx.doi.org/10.1207/s15327752jpa6802_7

Sheppard, R., Han, K., Colarelli, S., Dai, G., \& King, D. W. (2006) Differential Item Functioning by Sex and Age in the Hogan Personality Inventory. Assessment, 13, 442-453. http://dx.doi.org/10.1177/1073191106289031

Stevens, C. D., Guthrie, J. P., Ash, R. A., \& Coate, C. J. (2002). Does Personality Predict Preferred Managerial Style? Evidence from New Zealand and the United States. Asia Pacific Journal of Human Resources, 40, 322-344. http://dx.doi.org/10.1177/1038411102040003256

Tokar, D., \& Swanson, J. (1995). Evaluation of the Correspondence between Holland's Vocational Personality Typology and the Five Factor Model of Personality. Journal of Vocational Behaviour, 46, 89-108.

http://dx.doi.org/10.1006/jvbe.1995.1006 